\title{
Visual and acoustic performance of shading devices - real scale laboratory measurements
}

\author{
Tiberiu Catalina $^{1}{ }^{*}$, Alexandra Ene $^{1}$, and Andreea Biro $^{1,2}$ \\ ${ }^{1}$ Technical University of Civil Engineering, Faculty of Building Services, Bucharest, Romania \\ ${ }^{2}$ Arhiline Studio SRL, Bucharest, Romania
}

\begin{abstract}
There are several physical parameters that are taken into consideration when determining the level of agreeability of an enclosed space. For instance, when choosing the louvers for a room there are a multitude of criteria that might be considered such as colour, material or the degree of opacity. However, these apparently small fixtures may have a significant impact also on other apparently unimportant factors like the sound pressure level and the reverberation time. This paper aims to present different types of devices used to control the way daylight enters a room, from both the illuminance level and the acoustical point of view. During the experimental campaign, five of the most common types of louvers were examined regarding their main role of blocking the light and moreover their influence on the reverberation time and sound pressure level in the analysed chamber.
\end{abstract}

\section{Introduction}

Since people have been spending around $80-90 \%$ of their time in enclosed spaces, environmental comfort represents an important parameter which not only has a huge impact on people's health, but it also influences the occupants' perception of the interior space [1].

The use of daylight inside a building can help reduce the energy consumption and has a strong impact on important visual aspects. Depending on each room's destination, different illuminance levels are required. Using the free sun light can significantly reduce the energy consumption for lighting at the building level. On the other hand, too much uncontrolled daylight can have a negative impact on the workers ability to concentrate during certain parts of the day, due to the fact that high illuminance levels can lead to screen images [2]. Thus, different types of devices are used to reduce and control the daylight that enters a room. Daylight systems have the role of redirecting the sun light in order to prevent glare, but as a side effect they can cause the overheating of the interior environment. However, louvers have evolved in time becoming more and more effective.

Another way of keeping the heat inside during the cold months while reducing the cooling demand during the warm season is the use of low-e windows, which have been proved to be very effective when placed on the south and north façades [3].

The published literature shows that almost $25 \%$ of the total energy consumption of Australia is used by the office buildings, where $43 \%$ is consumed by the HVAC systems and $25 \%$ of the energy is dissipated in the lighting systems [4]. Hence, it is important to lower these values by using more of the free visual energy coming from the sun and at the same time prevent high values of illuminance levels entering the interior space, if possible, at the window level [4].

A survey on multiple tall buildings with large glazed façades in Malaysia showed that most of them are not equipped with external shading devices, leading to a non-uniform distribution of daylight and serious glare problems for the occupants. As a response to the problem the tenants of these buildings installed internal blinds and curtains and are using only artificial lighting [5].

According to the European Standard 12464-1, the visual requirements of a room should be accomplished without wasting energy and, at the same time, visual comfort should be achieved regardless of the energy consumption [6].

Studies showed that during the times when the sky is partially cloudy, the reflective louvers do not present results that are better than in the late afternoon, when external light has a lower value, resulting in a drop of the illuminance levels deep inside the room [7].

Daylight control becomes very important in climates with clear sunny skies, like the regions from the south of Europe. In these areas, users should have the possibility to adjust the slat angle of the blinds for a higher thermal and visual comfort [8].

In 2016 Gosh proposed to change the $1 \mathrm{~m}^{2}$ glazing of a south-facing wall from a double-glazed window to a $30 \%$ transparent suspended particle device (SPD) glazing. The results showed the fact that in a room without glazed surfaces the power needed to maintain the daylight factor at $4 \%$ is $0.7 \mathrm{kWh}$, but when using the suspended particle device glazing it is only $0.0048 \mathrm{kWh}$ [9].

\footnotetext{
* Corresponding author: tiberiu.catalina@gmail.com
} 


\section{Experimental campaign}

\subsection{Description of the illumination measurements set-up}

The experiments took place in two identical rooms - an emission room and a reception room - located at the INCERC Institute from Bucharest. The walls of the rooms are made of brick covered with cement plaster and have the maximum dimensions of $7.7 \mathrm{~m}$ length, $6.1 \mathrm{~m}$ width, $5.0 \mathrm{~m}$ height, resulting an area of $49 \mathrm{~m}^{2}$ and a total volume of $245 \mathrm{~m}^{3}$. The two spaces have a common wall, in which there is a double pane wooden window with $1.5 \mathrm{~m}$ length and $1.2 \mathrm{~m}$ height. Also, the experimental rooms have two identical timber doors.

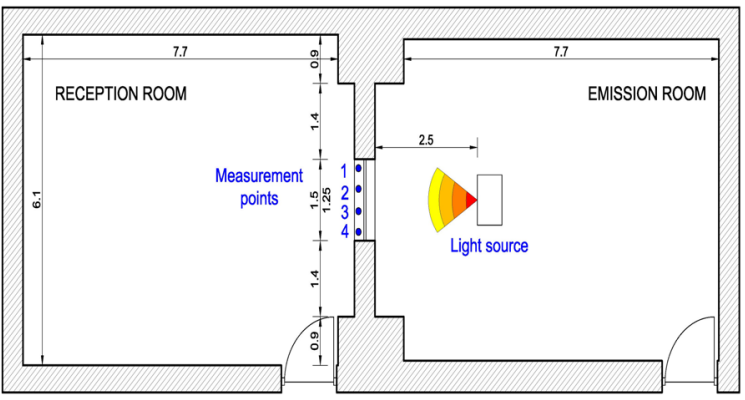

Fig. 1. 2D representation of the illumination experimental set-up

For the lighting experiments two sources of light $(50 \mathrm{~W}$ 3500 lumen projectors) were placed in the emission room at $2.5 \mathrm{~m}$ from the window, one at the height of $1.2 \mathrm{~m}$ while the second one at $1.5 \mathrm{~m}$. The illuminance levels were measured by the means of a Testo 480 equipment, with a measuring range between 0 and +100000 lux.

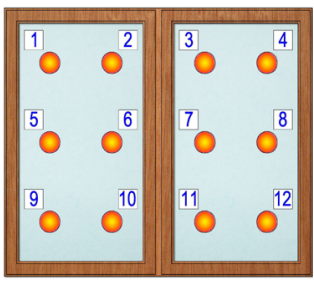

a.

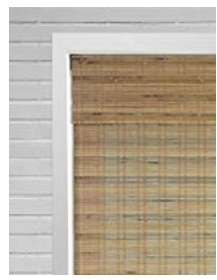

b.

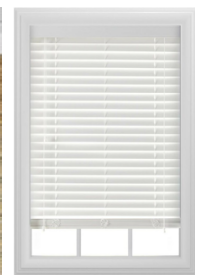

c.
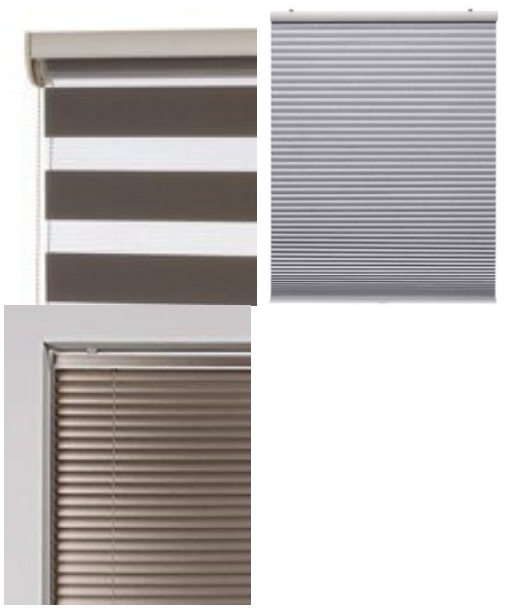

f.

Fig. 2. Window measurement points for the lighting experiment (a) and the analysed blinds: bamboo blinds (b), PVC venetian blinds (c), zebra textile blinds (d), cellular blinds (e), metallic venetian blinds (f)

First of all, the illuminance levels were measured in the emission room in all the 12 points indicated in Figure 2. Furthermore, the same points were measured in the reception room without the use of louvers. Then the illuminance levels were measured again in the reception room for five different types of blinds, specifically blinds made from bamboo, PVC venetian blinds, textile louvers, cellular panel blinds and in the end, aluminium venetian blinds.

\subsection{Description of the acoustic measurements set-up}

Further on, the reverberation time was measured in the reception room, where the blinds were placed, in order to point out the differences generated by introducing different materials into the interior space. The reverberation time was determined by the means of a Bruel\&Kjaer 2270 sound meter placed in the middle of the room, as shown in Figure 3. The studied shading devices were installed on the window one by one, and the reverberation time was determined for each one of them. Further on, the measurements were downloaded to a computer by the means of the "Measurement partner suite" software, in the form of an excel document.

During the same measurement campaign, we determined the sound pressure level (SPL) in the reception room when two Bruel\&Kjaer omni power sources were functioning in the emission room. As shown in Figure 3, the sound sources were placed in the back part of the emission room, at a distance of $1 \mathrm{~m}$ from the wall and $2 \mathrm{~m}$ away from each other. Meanwhile in the reception room, 5 receptors from the Bruel\&Kjaer "Pulse 3560-B-20" system were placed at a height of $1.5 \mathrm{~m}$ from the floor, distributed as follows: receptor R5 was placed at $1.5 \mathrm{~m}$ from the front wall, receptors $\mathrm{R} 3$ and $\mathrm{R} 4$ at $1.5 \mathrm{~m}$ from the side walls and $2 \mathrm{~m}$ away from $\mathrm{R} 5$ and finally receptors $\mathrm{R} 2$ and $\mathrm{R} 1$ were situated $2 \mathrm{~m}$ away from the back wall.

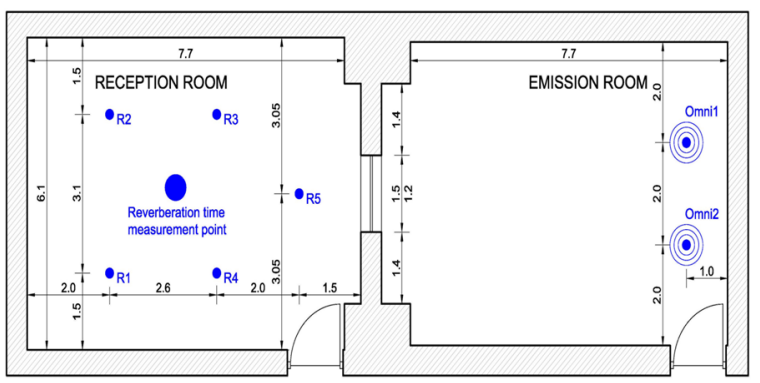

Fig. 3. 2D representation of the acoustic experimenta measurements set-up

\section{Results}




\subsection{Results of the illumination campaign}

Firstly, the illuminance levels were measured in the points indicated in Figure 2 for both the reception and the emission room, without any blinds attached to the window. The results showed that the illuminance levels in the emission room were higher with about 250 lux than the illuminance levels measured on the other side of the window, in the reception room. Furthermore, the highest level of illuminance measured in the emission room was 1000 lux, determined in point 6 , in the middle part of the window. On the other hand, in the reception room the highest level of illuminance determined in point 6 was 680 lux, so that the highest difference between the illuminance levels measured in the two experimental rooms was 320 lux.

After the measurements were repeated with the studied shading devices attached to the window, the results showed that the highest illuminance levels measured in the reception room were in the case of the bamboo blinds, around 250 lux on the upper part of the window and lower values for the measuring points located on the middle and lower part of the window. The textile blinds presented values that were approximately constant around 190 lux for all measuring points.

However, important variations in the results were observed in the case of the plastic blinds. In the upper points, when the blinds were closed with the blades facing upwards, the illuminance values were higher than when the blinds were closed with the blades facing downwards. The situation substantially changed for the middle and lower measuring points, which presented higher levels of illuminance with the blades closed downwards. This happened because the blades cannot reach the vertical angle at the same time, thus allowing light to pass through the small gaps between them.

The best results were obtained with the aluminium blinds attached to the window. In this case, the illuminance levels reached with difficulty 50 lux even if the blinds were closed with the blades facing up or down. Likewise, it can be observed that the illuminance levels were very similar in all 12 measuring points.

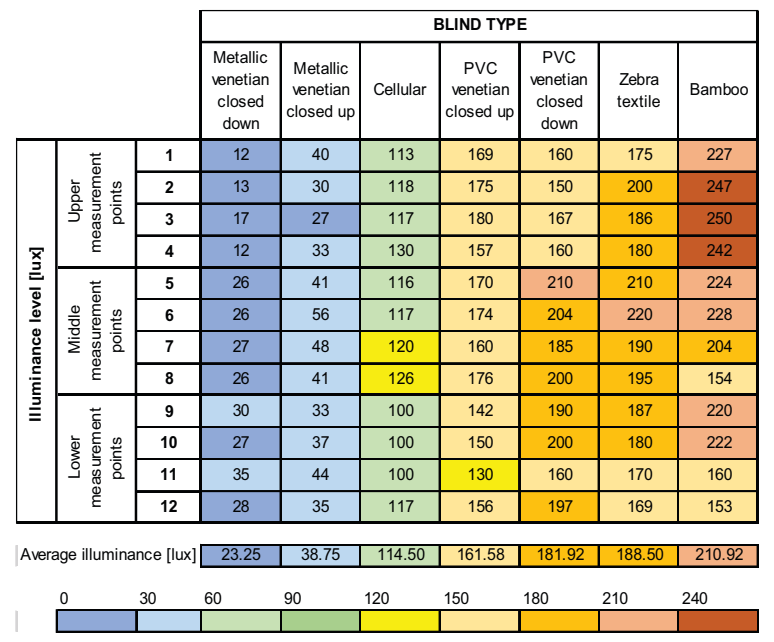

Fig.4. Illuminance levels for the 12 measurements points

\subsection{Results of the acoustical experimental campaign}

As the reverberation time is an important parameter for indoor environment, we have conducted an experimental campaign on the assessment of this factor.

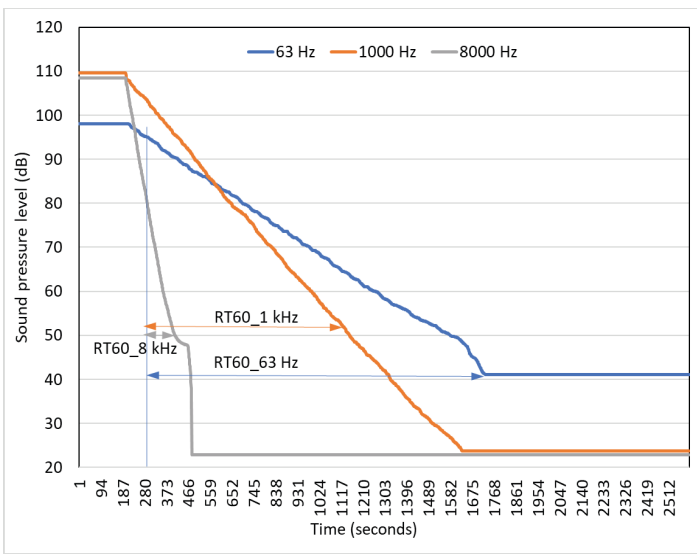

Fig.5. Reverberation time decay for 63,1000 and $8000 \mathrm{~Hz}-$ with bamboo blinds

For each case the procedure to determine the RT levels was based on the interrupted method, which represents an artificial noise source introduction and its removal. The RT is the time taken for the sound to decay by $60 \mathrm{~dB}$ when the source is removed.

The RT is modified by the volume and geometry of the room, the walls/floor/ceiling materials and all objects (including the occupants) within the room. When the RT is too high numerous problems can occur, among which the most severe being the unintelligibility of speech. The optimum reverberation time depends on the size and destination of the space.

As it can be seen from Figure 5, the highest values were obtained at low frequencies, while minimum reverberation times of 1.0 seconds were found for higher frequencies $(\mathrm{f}=8000 \mathrm{~Hz})$.

The measurement results showed that for the 1000 $\mathrm{Hz}$ frequency, which presents the results closest to the human ear, the reverberation time had its highest value of $4.76 \mathrm{~s}$ when using the bamboo blinds. Very similar to them, the aluminium and plastic blinds presented $4.71 \mathrm{~s}$, respectively $4.73 \mathrm{~s}$. The lowest value of $4.4 \mathrm{~s}$ was obtained with the panel blinds. On the other hand, for the smaller frequencies, the reverberation time changed drastically, showing its lowest value of $7.8 \mathrm{~s}$ in the case of the bamboo blinds, while the highest value of $8.6 \mathrm{~s}$ was determined for the plastic blinds. Furthermore, at high frequencies the reverberation time presented almost the same values for all the analysed blinds. It can be 
concluded that the bamboo blinds perform best for low frequencies, having the highest absorption coefficient among all the studied blinds. For medium frequencies textile and panel blinds have the best sound absorption while for higher frequencies all blinds are similar.

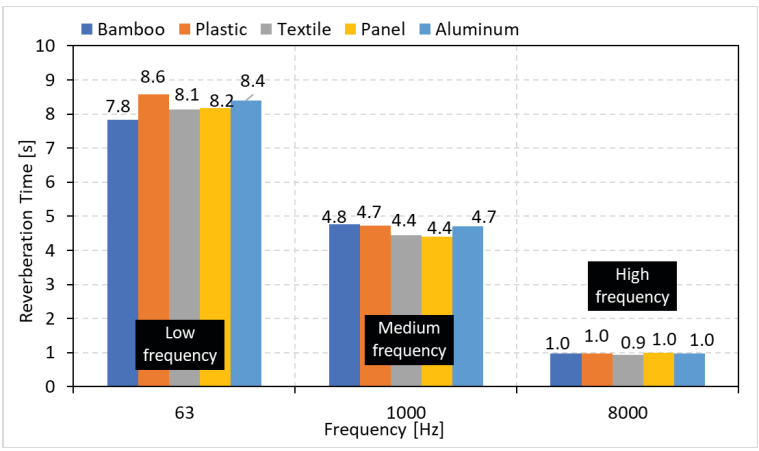

Fig. 6. Reverberation time graph for the analysed blinds (low, medium and high frequency)

Table 1. Reverberation time measurements

\begin{tabular}{|c|c|c|c|c|c|c|c|c|}
\hline $\mathbf{f ~ [ H z ]}$ & $\mathbf{6 3}$ & $\mathbf{1 2 5}$ & $\mathbf{2 5 0}$ & $\mathbf{5 0 0}$ & $\mathbf{1 k}$ & $\mathbf{2 k}$ & $\mathbf{4 k}$ & $\mathbf{8 k}$ \\
\hline Bamboo & 7.83 & 8.47 & 6.1 & 5.69 & 4.76 & 3.48 & 2.08 & 0.97 \\
\hline Plastic & 8.57 & 8.29 & 6.41 & 5.65 & 4.73 & 3.55 & 2.17 & 0.97 \\
\hline Textile & 8.14 & 8.57 & 6.52 & 5.36 & 4.44 & 3.41 & 2.09 & 0.94 \\
\hline Panel & 8.17 & 8.73 & 6.19 & 5.5 & 4.4 & 3.29 & 2.05 & 1 \\
\hline Alum. & 8.39 & 8.38 & 6.7 & 5.9 & 4.71 & 3.38 & 2.12 & 0.97 \\
\hline
\end{tabular}

In addition to the reverberation time measurements, we were also interested to see the impact of the sound pressure levels inside the reception room in the case of the 5 studied louvers (see Table 2). Firstly, the results showed that receptor R5 that was placed in front of the analysed window presented the highest level of Aweighted global SPL. As we moved away from the window the SPL seemed to present smaller values, but the differences were not very significant. The emission room sound source had a value of $93.76 \mathrm{~dB}(\mathrm{~A})$.

Table 2. Sound pressure levels for the 5 measurement points

\begin{tabular}{|c|c|c|c|c|c|}
\hline Point & Bamboo & Panel & Textile & Plastic & Alum. \\
\hline 1 & 75.9 & 75.3 & 75.5 & 76.2 & 75.5 \\
\hline 2 & 75.6 & 75.1 & 75.5 & 75.9 & 75.8 \\
\hline 3 & 76.3 & 75.9 & 75.9 & 76.4 & 76.0 \\
\hline 4 & 76.0 & 75.6 & 75.5 & 75.9 & 75.8 \\
\hline 5 & 77.3 & 76.5 & 77.0 & 77.4 & 77.1 \\
\hline Average & 76.2 & 75.7 & 75.9 & 76.4 & 76.0 \\
\hline
\end{tabular}

Moreover, when comparing the SPL obtained with different types of blinds, it can be pointed out that when using the plastic blinds the SPL in the reception room accomplished its highest value for receptor R5 of 77.4 $\mathrm{dB}(\mathrm{A})$. Furthermore, the bamboo blinds had the second highest values corresponding to $77.3 \mathrm{~dB}(\mathrm{~A})$ for receptor $\mathrm{R} 5$ and $75.6 \mathrm{~dB}(\mathrm{~A})$ for receptor $\mathrm{R} 2$ placed at the back of the room. While the first two places were occupied by the bamboo and the plastic blinds as having the lowest sound absorbing coefficients, the panel blinds showed the best acoustical results leading to a value of the SPL of $76.5 \mathrm{~dB}(\mathrm{~A})$ for receptor $\mathrm{R} 5$, almost $1 \mathrm{~dB}(\mathrm{~A})$ less than when the plastic blinds were used.

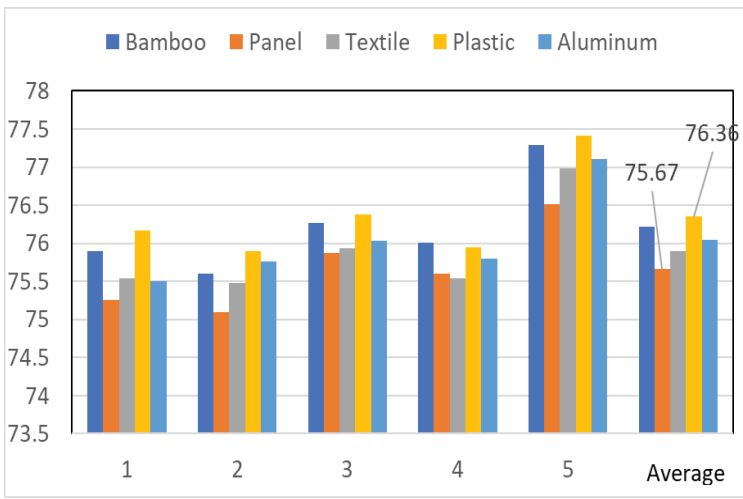

Fig. 7. Global A-weighted sound pressure levels for the analysed blinds

The determination of sound insulation was realized in accordance with International standard ISO 140 using the following equation:

where

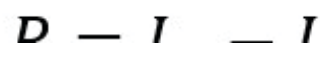

$\mathrm{L}_{1}=$ average sound pressure level in the source room $\mathrm{L}_{2}=$ average sound pressure level in the source room $\mathrm{S}=$ area of the façade (wall + glazing)

$\mathrm{A}=$ equivalent absorption area in the receiving room

The equivalent absorption area A was evaluated from:

where

$\mathrm{V}=$ receiving room volume

$\mathrm{RT}=$ reverberation time in the receiving room

For all the tested cases of blinds measurements on $\mathrm{L}_{1}$, $\mathrm{L}_{2}$ and $\mathrm{RT}$ were realized, therefore it was possible to calculate an average sound transmission index.

Table 3. Sound attenuation index for the 5 analysed shading devices

\begin{tabular}{|c|c|c|c|c|c|}
\hline Parameter & Bamboo & Panel & Textile & Plastic & Alum. \\
\hline $\mathrm{L}_{1}-\mathrm{L}_{2}$ & 17.55 & 18.10 & 17.87 & 17.40 & 17.72 \\
\hline $10 \log \mathrm{S} / \mathrm{A}$ & 6.00 & 6.10 & 6.01 & 5.99 & 6.12 \\
\hline $\mathrm{R}$ & 23.55 & 24.20 & 23.87 & 23.39 & 23.84 \\
\hline
\end{tabular}

As it can be noticed from table 3, the best sound insulation was provided by the cellular panel blind, due to its sound absorption proprieties, while the plastic blind had the lowest sound attenuation index among the 5 types of analysed blinds. 


\section{Conclusions}

Within this experimental campaign we aimed to compare the five most common types of blinds used inside dwellings from acoustical and illuminance levels points of view. The measurements were held in a special real scale experimental facility presenting two identical rooms separated by a structurally dissociated wall. The results of the lighting measurements showed the highest illuminance levels in the reception room in the case of the bamboo blinds, with an average of 210 lux for the 12 measuring points. On the other hand, the aluminium blinds presented by far the lowest values of illuminance, with the blades closed either upwards or downwards, the illuminance levels in the reception room didn't exceed 56 lux. Regarding the acoustical properties of the materials, the new type of panel blinds seemed to be the best option in hand as the SPL obtained inside the reception room when these louvers were used was the lowest. Moreover, according to the reverberation time determinations the textile and panel blinds showed the lowest values at the frequency of $1000 \mathrm{~Hz}$ both obtaining $4.4 \mathrm{~s}$.

\section{References}

[1] Al horr Y, Arif M, Katafygiotou M, Mazroei A, Kaushik A, Elsarrag E, Impact of indoor environmental quality on occupant well-being and comfort: A review of the literature, International Journal of Sustainable Built Environment, 2016, $5,1-11$

[2] Liu T, Lin C, Huang K, Chen Y, Effects of noise type, noise intensity, and illumination intensity on reading performance, Applied Acoustics, 2017, 120, 70-74

[3] Zomorodian Z, Tahsildoost M, Assessment of window performance in classrooms by long termspatial comfort metrics, Energy and Buildings, 2017, 134, 80-93

[4] Lavin C, Fiorito F, Optimization of an external perforated screen for improved daylighting and thermal performance of an office space, Procedia Engineering,2017, 180, 571 - 581

[5] Lim Y, Heng C, Dynamic internal light shelf for tropical daylighting in high-rise office buildings, Building and Environment, 2016, 106, 155-166

[6] EUROPEAN STANDARD 12464-1, Light and lighting Lighting of work places - Part 1: Indoor work places, 2002

[7] Leung T, Rajagopalan P, Fuller R, Performance of a daylight guiding system in an office building, Solar Energy, 2013, 94, 253-265

[8] Gomes G, Santos A, Rodrigues M, Solar and visible optical properties of glazing systems with venetian blinds: Numerical, experimental and blind control study, Building and Environment, 2014, 71, 47-59

[9] Ghosh A, Norton B, Duffy A, Daylighting performance and glare calculation of a suspended particle device switchable glazing, Solar Energy ,2016, 132, 114-128

[10] Chi A, Moreno D, Navarro J, Design optimization of perforated solar façades in order to balance daylighting with thermal performance, Building and Environment, 2017, 125, $383-400$

[11] De Graaf T, Dessouky M. Mülle H, Sustainable lighting of museum buildings, Renewable Energy, 2014, 67, 30-34

[12] Bunning M, Crawford R, Directionally selective shading control in maritime sub-tropical and temperate climates: Life cycle energy implications for office buildings, Building and Environment, 2016, 104, 275-285

[13] Diaz C, Pedrero A, The reverberation time of furnished rooms in dwellings, Applied Acoustics, 2005, 66, 945-956 